\title{
The Pantheon, eye of Rome, and its glimpse of the sky
}

\author{
Amelia Carolina Sparavigna ${ }^{1}$ and Lidia Dastrù̀ \\ 1. Politecnico di Torino \\ 2. Independent Researcher
}

\begin{abstract}
The only natural light source of the Pantheon in Rome is its Oculus, a large opening at the top of the vault. Some literature proposed that the rays of the sun, passing through the Oculus, were acting as they could do in a huge sundial. The sun has been also imagined as being involved during some rituals made by the Roman emperors in the temple, to emphasize the celebrations of the foundation of Rome. Besides to the sun, the temple could also have been linked to the heavens and the stars passing close to the Zenith. Inside this temple, which we could imagine as a huge eye, the gods were guarding the motion of the universe, Mundus, of which the city, Caput Mundi, was the head. In fact, a possibility exists that the architect who planned the temple had been inspired by the form of the human eye to create a building representative of the link between Rome and the heavens, exactly in the place where Romulus ascended to them. In this article, besides proposing this idea, we give also some simulations made by means of the software planetarium Stellarium, of the night sky and the stars visible through the Oculus at the time of the Emperor Hadrian, who built the temple that we see today.
\end{abstract}

Keywords: Archaeoastronomy, Zenith Passage of the Stars, Stellarium.

Written in Turin and submitted HAL on 27 May 2018.

The Pantheon is an ancient temple in Rome. The present building, used today as a church, was built on the site of an earlier temple commissioned by Marcus Agrippa during the reign of Augustus. The Pantheon of Agrippa was destroyed in a huge fire in the year 80 AD. Domitian rebuilt a temple, which was burnt again in 110 AD. The new Pantheon was completed by the Emperor Hadrian and probably dedicated about 126 AD [1]. The design is circular, having a portico with columns of Corinthian granite. The Pantheon dome is made of concrete [2]. At the top of the dome, we find an Oculus, a round opening which is the main source of natural light inside the temple (Figs. 1 and 2). The Oculus has a diameter of $9 \mathrm{~m}$, whereas the building is $43 \mathrm{~m}$ tall [1].

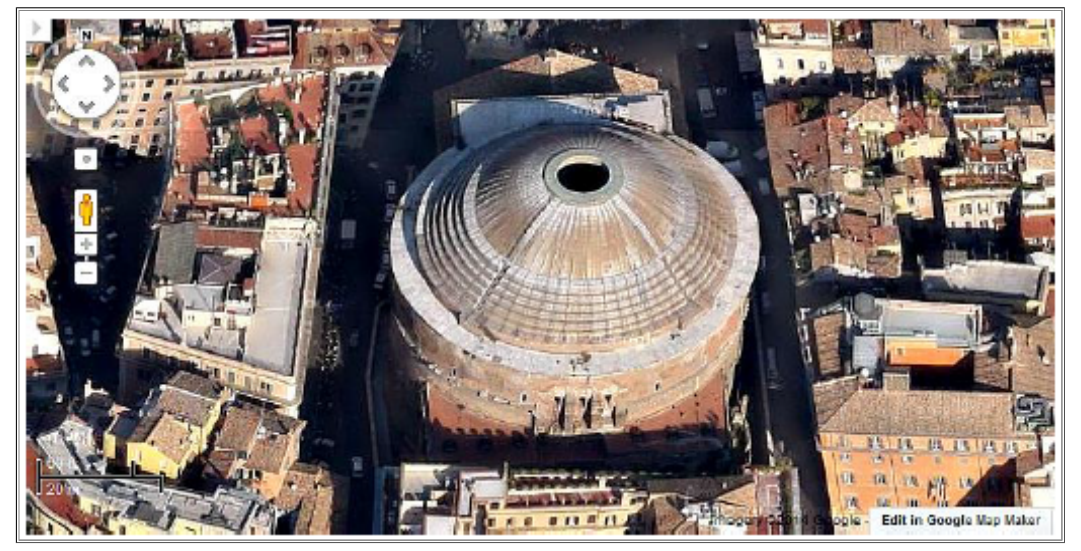

Figure 1 - The coffered concrete dome of the Pantheon in Rome, with a central opening (Oculus) to the sky, as seen from satellite (courtesy: Google Maps). 


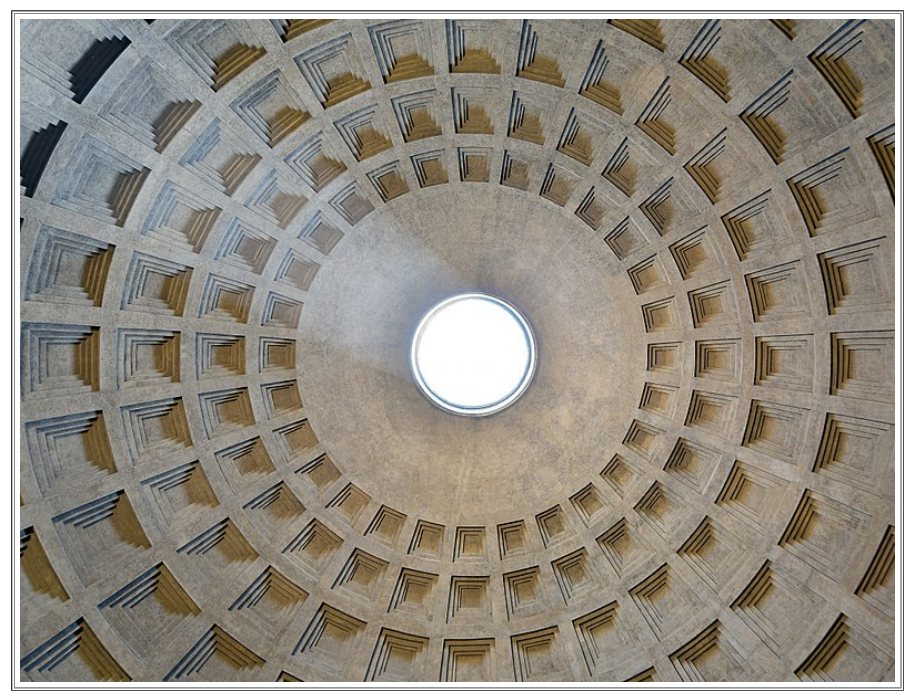

Figure 2 - The Oculus in the dome (courtesy Wikipedia, User Livioandronico2013).

The Pantheon is the subject of several works discussing the link between its architecture and astronomy [3-21]. In a short pamphlet [3], Fausto Masi proposed the Pantheon as an astronomical instrument, to determine the altitude of the sun. The pamphlet is containing sketches showing the position of the shaft of sunlight passing through the roof at the solstices and the equinoxes (the Figure 3 shows a drawing inspired by a sketch in [3], concerning equinoxes).

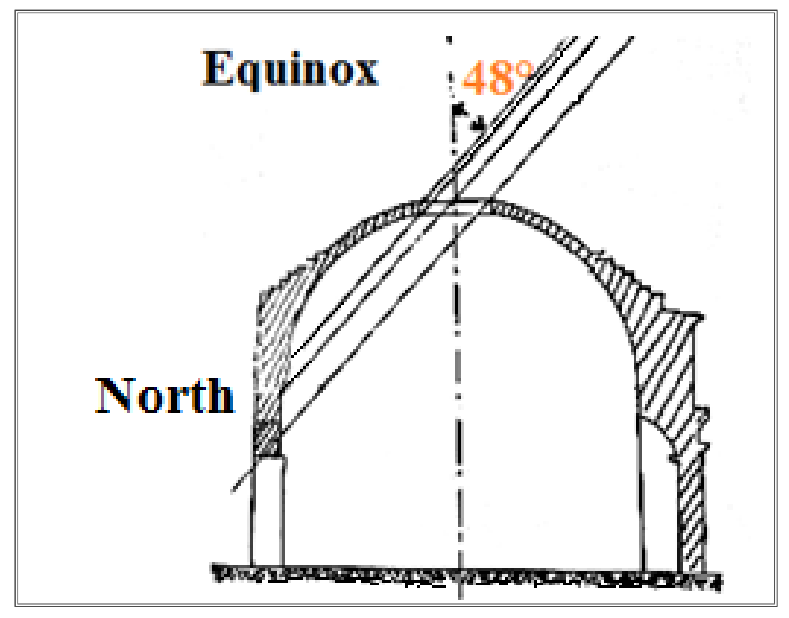

Figure 3 - An example of drawings that we can see in Ref.3.

Among the given references, other articles are concerning the sun and the light entering the temple. In particular, in [4] we find mentioned the role on the sun on April 21, the Birthday of Rome. In [4], we can read that "Un ulteriore riferimento va fatto alle condizioni che si verificano nel Pantheon il giorno 21 aprile, Natale di Roma. Infatti alle 12.00 (ora solare) all'interno del monumento, la penetrazione del sole crea una sensazione eccezionale. I raggi del sole abbagliano il visitatore all'ingresso, il quale perde la percezione materica sovrastante e riceve una immagine davvero suggestiva". That is, we have to consider the conditions that occur 
in the Pantheon on 21 April, Birthday of Rome. In fact, at noon, inside the monument, the rays of the sun create an exceptional sensation. The rays dazzle the visitor at the entrance, who loses the perception of the overlying structure of the building.

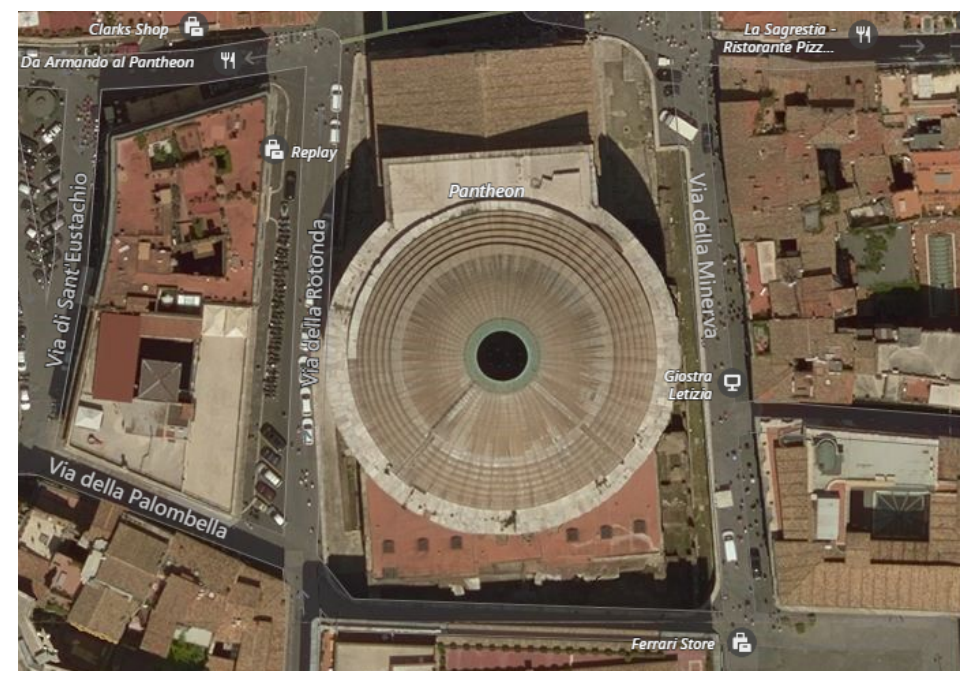

Figure 4 - The entrance of the building is not perfectly aligned along the cardinal direction (courtesy: Bing Maps).

This leads us to argue - Ref. 4 tells - that, according to the period and the complexity of the construction, in choosing a North orientation of the entrance of the building, the architects could have considered astronomical references and positioned the axis of the door and other architectural elements accordingly [4].

Let us note that the ancient Romans were sure that April 21, the day of the festival sacred to Pales, goddess of shepherds, was also the day of the foundation of Rome. Therefore, any link of this day to architectures comes as no surprise. The role of the sun in the Pantheon on April 21 is also mentioned in [20]. The authors are proposing that the symbolic action of the sun on that day was that of putting "Rome among the Gods". "If we suppose, as seems likely, that the emperor was celebrating this precise day there, then his entrance "together with the sun" would have been a symbolic link between the people and the Gods" [20].

The Pantheon that we see today was built at the time of Hadrian, but it seems reasonable to imagine that some rituals existed - and related hierophanies linking the Pantheon to the sun - even at the time of Augustus. As told in [21], some recent discoveries tell that, in the area in front of the Pantheon, there are the original stairs of the previous Augustan temple. According to Eugenio La Rocca, Accademia Nazionale dei Lincei, these findings testify that the Pantheon rebuilt by Hadrian, that is the temple that we see today, has preserved the original North orientation of the temple of Augustus. Also the monumental bronze door is that of the Augustan building. La Rocca continues explaining that there are all the reasons to suppose that any phenomenon concerning the rays of the sun existed also in the Pantheon of Augustus, a temple that had a similar conformation, not so complex but with a similar façade. "Why this mise-en-scène?" - Reference 21 is asking. "It is the political program of Augustus - highlights La Rocca - to restore his appearance as the new founder of the city, in the sign of peace", in an authentic "solar theater" [21].

As we can see from the Figure 4, the entrance of the Pantheon is not perfectly aligned along the cardinal direction. There is a difference of about three degrees. Probably, this is due to the fact that the entrance of the Pantheon of Hadrian was oriented towards the Mausoleum of Augustus [20]. Let us add the possibility that, 
any time an emperor entered the Pantheon on April 21, he was imagined accompanied by the spirit of Augustus coming from his mausoleum to celebrate the foundation of Rome again.

Besides the sun and related rituals, let us also consider the Oculus and the night sky. The temple, like a huge human eye, had its pupil which was observing the stars passing at the Zenith of Rome. Let us remember that the sun and the moon, at the latitude of Rome, cannot reach the zenith position. If we are precisely at the center of the floor of the Pantheon, through the Oculus we can see an angle 10 degrees wide, as given in the Figure 5. Therefore, let us investigate by means of the planetarium software Stellarium what were the stars observed by the Roman emperors.

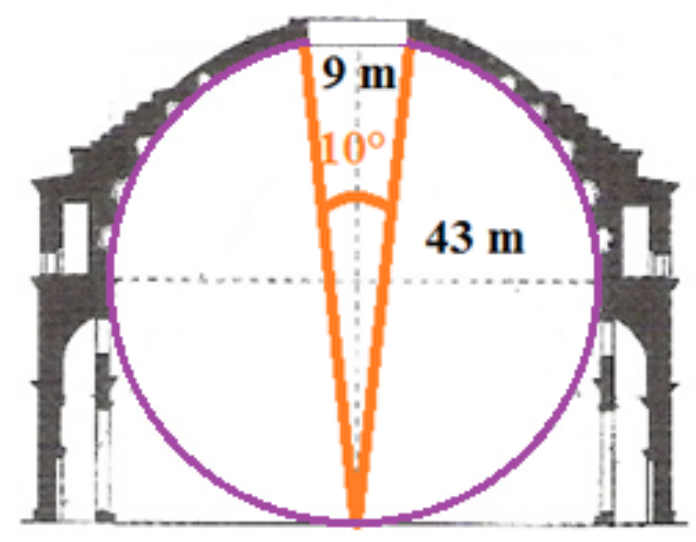

Figure 5 - The Pantheon is $43 \mathrm{~m}$ tall. The diameter of the dome is of 43 meters. The Oculus has a diameter of 9 $\mathrm{m}$. If we are at the center of the floor, we can see an angle 10 degrees wide.

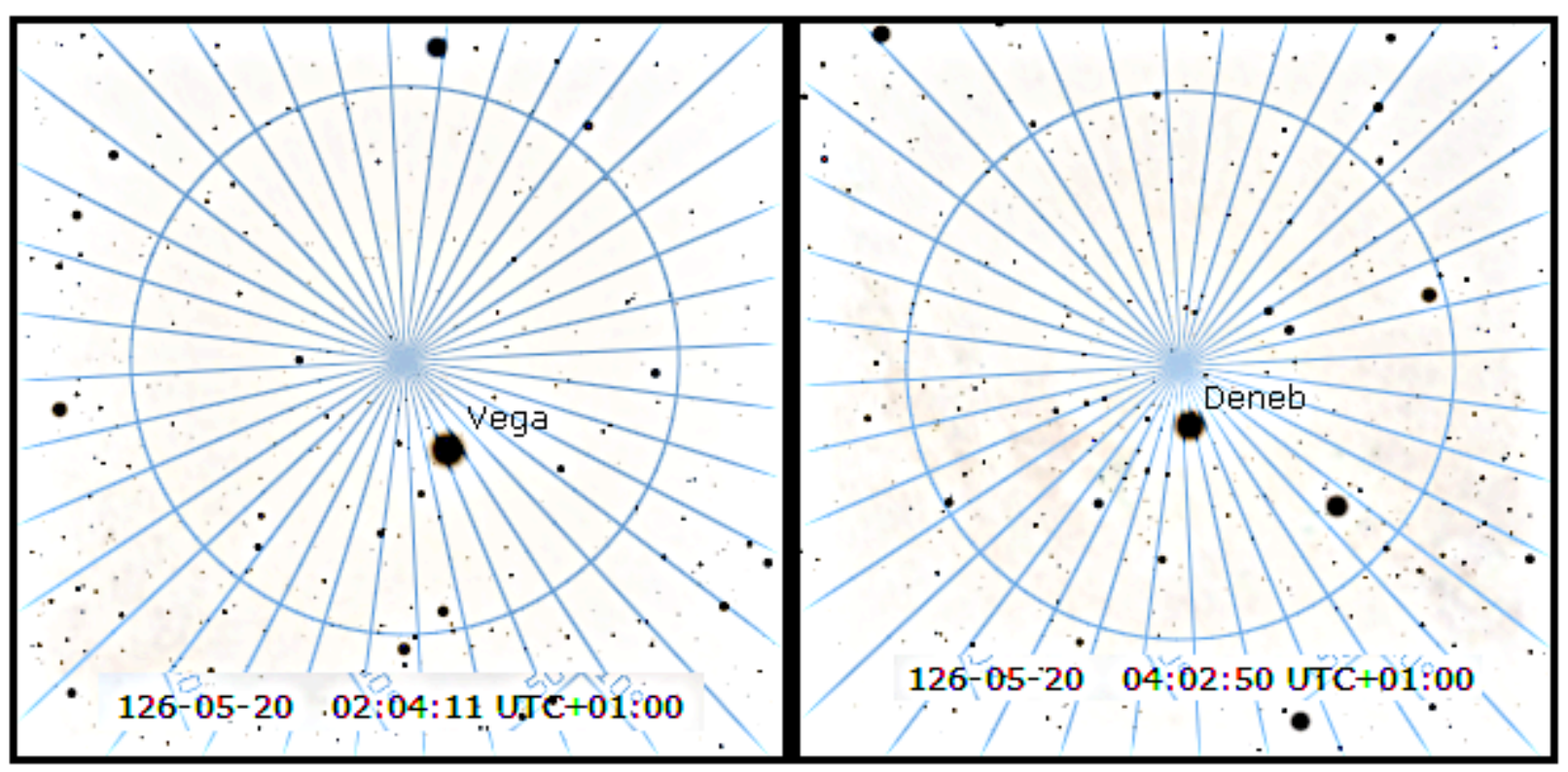

Figure 6 - Here we can see, simulated by Stellarium, some stars passing close to the Zenith of Rome. On the left, 20 May, 126 AD (Vega); on the right, the same night, after two hours (Deneb). 
The Stellarium software - an open-source free-software planetarium available for Linux, Windows, and macOS can show us the bright stars near the Zenith. Let us observe the sky during a night of $126 \mathrm{AD}$, the year of the probable dedication of the temple. In the Figures $6-8$, the circle of the frame of reference, which giving altitude and azimuth, is at 10 degrees from the Zenith. If we consider $D$ the diameter of this circle in Stellarium, the Oculus has to be imagined appearing with a diameter $\mathrm{D} / 2$.

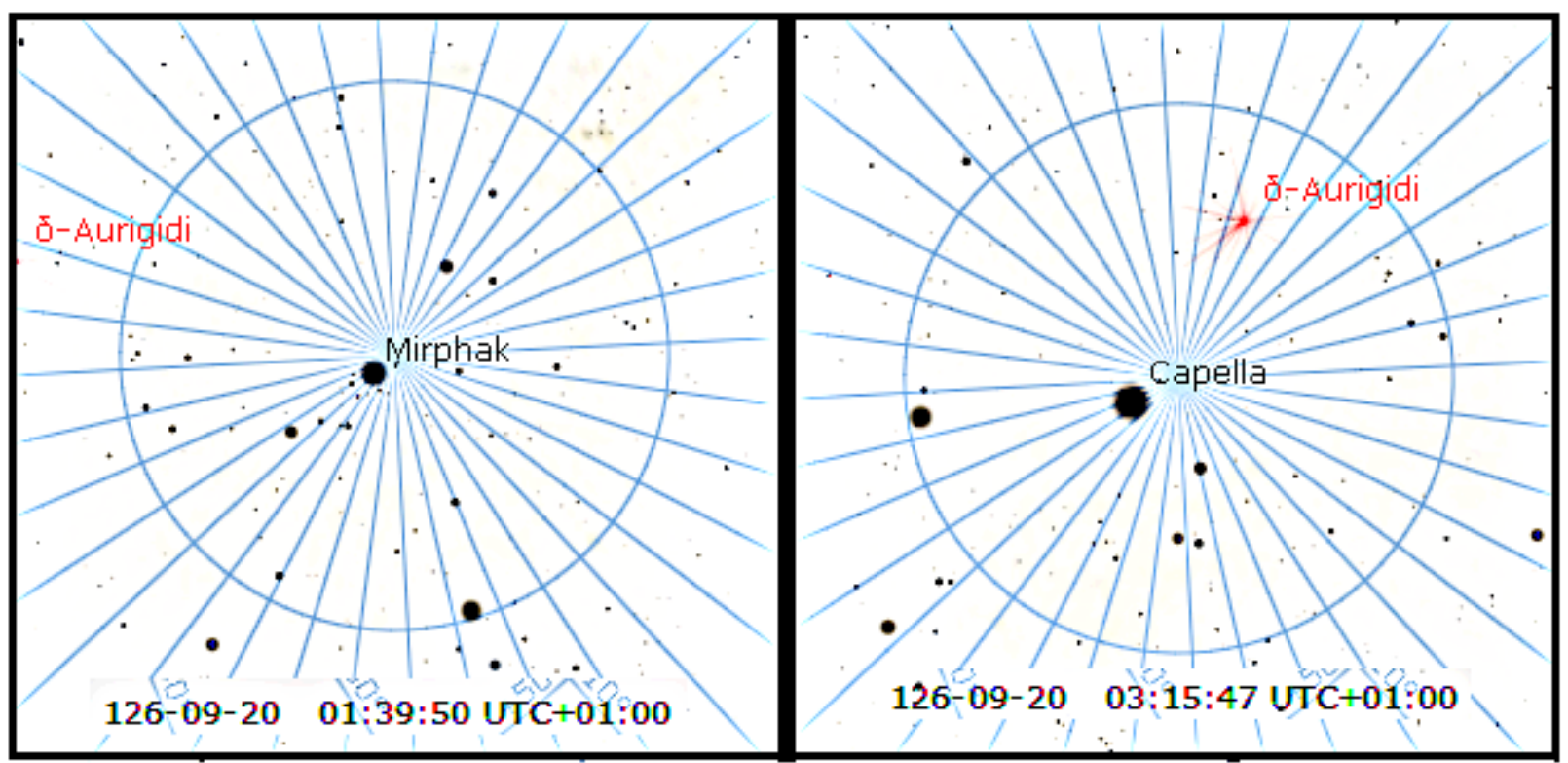

Figure 7 - On the left, 20 September, 126 AD (Mirphak); on the right, the same night, after one hour and 35 minutes (Capella).

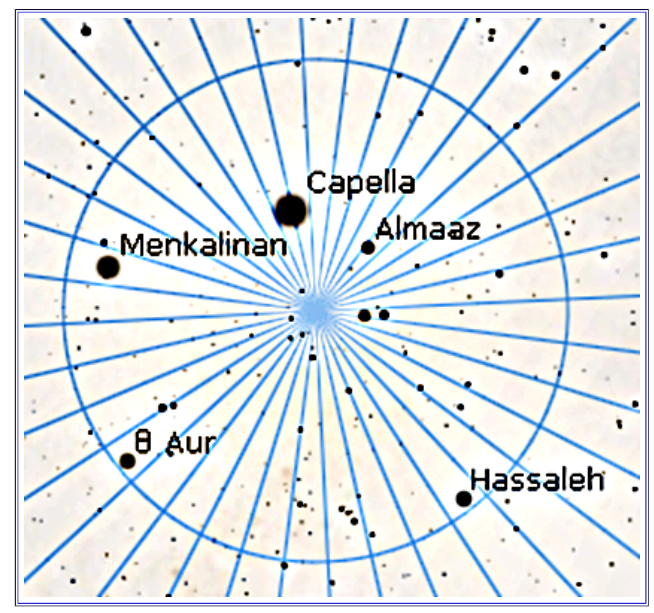

Figure 8 - Today, Capella has not a zenith passage.

An observer in the temple was able to see the zenith passage of these stars during the year, and easily measure the time, during the night. From the Figures 6 and 7, we can see Vega, Deneb, Mirphak and Capella passing 
close to the zenith, in the frame of the pupil of the temple (due to the precession of the Earth's axis, today Capella is not a zenith star, Figure 8). Therefore, inside this temple, which could be imagined as a huge eye, the gods had the possibility to guard the motion of the world of which the city of Rome was the head, that is, the Caput Mundi.

Like a human eye, the Pantheon has a field of view (Fig.9) which is larger than that given in the Figure 5, and then other stars and related asterisms were and are visible (in a previous discussion [22], we have considered only the Zenith). Let us remember that Capella is Alpha Aurigae, the brightest star in the constellation of Auriga. It is the sixth-brightest star in the night sky, and the third-brightest in the northern celestial hemisphere after Arcturus and Vega. Beside the constellation of the Auriga, in the frame of the Oculus of the Pantheon, other constellations were passing. We had Perseus, of which the brightest star is Mirphak. Also the mirror of the vain queen Cassiopeia was passing at the center of the Oculus (Fig.10). Then we have the Cygnus, the northern constellation lying on the plane of the Milky Way. Deneb is the bright star in the tail of the constellation (Fig.10).

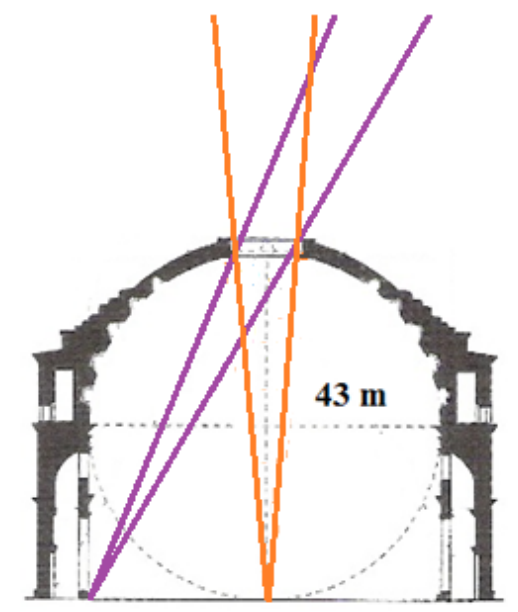

Figure 9 - The field of view is larger than the angle of Fig.5.
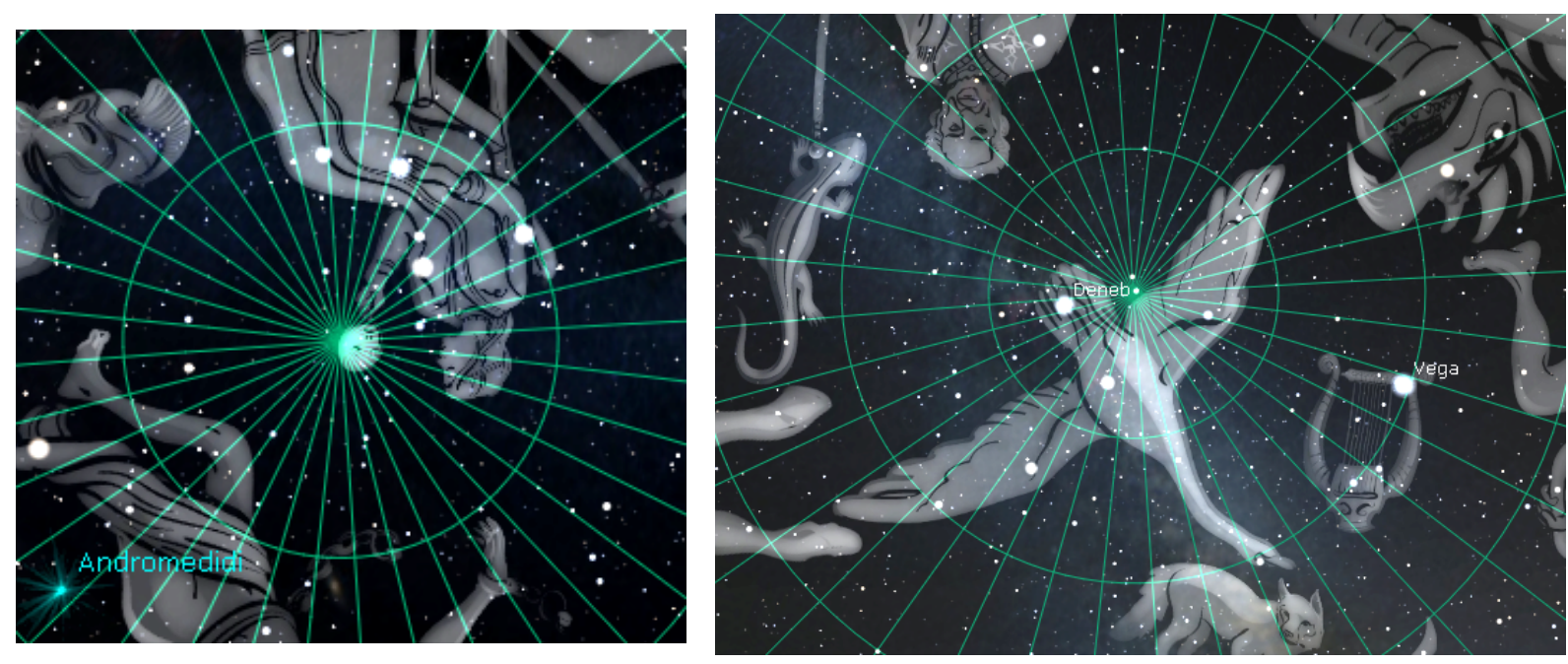

Fig 10 - The mirror of Cassiopeia on the left and the Cygnus on the right. 
Let us consider again Figures 1 and 5, which are showing the black appearance of the Oculus. It is like the pupil located in the center of the iris of an eye, which appears black because the light entering the pupil is either absorbed by the tissues inside the eye or absorbed after some diffusion within the eye, so that it mostly misses exiting the narrow pupil. Therefore, as we imagine the Pantheon seen from above, to the gods in the heavens the building was like an eye at the center of the Campus Martius in Rome. Let us note that it was from this place that Romulus ascended to heaven, and that it "could not have been coincidental that this very area was chosen by Agrippa as the site of the Pantheon, which functioned as a dynastic temple honoring the celestial gods and Augustus' deified father, Julius Caesar" [23].

Let us conclude our discussion on the Pantheon of Rome with the following suggestion. In our opinion, the possibility exists that the human eye was the model for the architecture of the Pantheon. Actually, examples of parts of the human body used as models for architectures exist [24], and among them we find the well-known case of the colonnades designed by Gian Lorenzo Bernini for St Peter's Square. As told by Bernini himself, the colonnades were designed to surround people as "the maternal arms of Mother Church", in his Baroque theatricality vision of the architecture [25]. Therefore, also the architect of the ancient Rome that planned the Pantheon could have had the same symbolic vision of architecture. We can imagine that the he planned the building like a human eye, not only inspired by the function of the light in it, but also by its anatomy. In this manner he created a temple linking Rome to the heavens, in the form of an eye that could observe the motion of the universe.

\section{References}

[1] Terenzio, Alberto (1935). Pantheon. Enciclopedia Italiana. Available from http://www.treccani.it/ enciclopedia/ pantheon_(Enciclopedia-Italiana)/

[2] Sparavigna, A. C. (2014). Some Notes on Ancient Concrete. International Journal of Sciences, 3(2), 1-6.

[3] Masi, F. (1996). The Pantheon as an Astronomical Instrument. ElLS. Roma.

[4] Belardi, G., \& Carbonara, G. (2006). II Pantheon: storia, tecnica e restauro. Betagamma, 2006.

[5] Lim, C. S. (1998). The Formal Analysis of Pantheon in Rome in Relation to the Solar Angles. Journal of architectural history, 7(4), 191-198.

[6] de Fine Licht, K. (1968). The Rotunda in Rome: a study of Hadrian's Pantheon. Jutland Archeological Society.

[7] Joost-Gaugier, C. L. (1998). The iconography of sacred space: A suggested reading of the meaning of the Roman pantheon. Artibus et Historiae, 21-42.

[8] MacDonald, W. L. (2002). The Pantheon: design, meaning, and progeny. Harvard University Press.

[9] Meeks, C. L. V. (1960). Pantheon paradigm. journal of the Society of Architectural Historians, 19(4), 135-144. [10] Nicoletta, L., \& Virgili, P. (2016). The Urban Set of the Pantheon and the Mausoleum of August in Rome, between Architectural and Astronomical Symbolism. Mediterranean Archaeology and Archaeometry, 16(4), 249-255.

[11] Jones, M. W. (2013). Who Built the Pantheon? Agrippa, Apollodorus, in Hadrian: Art, Politics and Economy, ed. Thorsten Opper, British Museum Research Publication 175 (London, 2013): 31-49.

[12] Swetnam-Burland, M. (2013). Pantheon, Rome. The Encyclopedia of Ancient History.

[13] Wilkins, P. (2004). The Pantheon as a globe-shaped conception. Nexus Network Journal, 6(1), 78-84.

[14] Sperling, G. (1997). Das Pantheon in Rom, Abbild und Mass des Kosmos. Ars Una, ISBN-10: 389391854X, ISBN-13: 978-3893918546

[15] Aliberti, L., \& Alonso-Rodríguez, M. Á. (2017). Geometrical Analysis of the Coffers of the Pantheon's Dome in Rome. Nexus Network Journal, 19(2), 363-382.

[16] Sperling, G. (2004). Early Orchestration: The Pantheon as a resonance element. Nexus Network Journal, 6(1), 65-69. 
[17] Sperling, G. (2015). The "Quadrivium" in the Pantheon of Rome. In Architecture and Mathematics from Antiquity to the Future (pp. 215-227). Springer International Publishing.

[18] Martines, G. (2000). The relationship between Architecture and Mathematics in the Pantheon. Nexus Network Journal, 2(1-2), 57-62.

[19] Hannah, R. (2009), The Pantheon as a Timekeeper, British Sundial Society Bulletin Vol 21(4) pp.2-5

[20] Hannah, R., Magli, G. (2011), The role of the sun in the Pantheon's design and meaning, Numen 58, $n^{\circ} 4$, 486-513.

[21] Pantheon, svelato il segreto della cupola. II Messaggero, 6 Marzo 2014. https://www.ilmessaggero.it/roma/cultura/pantheon_cupola_roma-318179.html

[22] Sparavigna, A. C. (2017). The Zenith seen through the Oculus of the Pantheon. March 2017. Researchgate. DOI: 10.13140/RG.2.2.17694.95041

[23] Pollini, J. (2012). From Republic to Empire: Rhetoric, Religion, and Power in the Visual Culture of Ancient Rome. University of Oklahoma Press, Nov 20, 2012.

[24] Kausel, C. L. (2007). Evocation Of The Head And Brain In Old Vaulted Buildings. International Journal of Design \& Nature and Ecodynamics, 2(3), 258-276.

[25] Sparavigna, A. C. (2015). Light and Shadows in Bernini's Oval of Saint Peter's Square. November 8, 2015. PHILICA Article number 540. Available at SSRN: https://ssrn.com/abstract=2742281 